\title{
Prevalence of Spontaneous Asymptomatic Facial Nerve Canal Meningoceles: A Retrospective Review
}

\author{
(D).C. Benson, (DK. Krecke, (D).R. Geske, (D). Dey, (D) M.L. Carlson, (D). Van Gompel, and (D).I. Lane
}

\begin{abstract}
BACKGROUND AND PURPOSE: The prevalence of patent facial nerve canals and meningoceles along the facial nerve course is unknown. This study aimed to assess the frequency of such findings in asymptomatic patients.

MATERIALS AND METHODS: A retrospective review was completed of patients with high-resolution MR imaging of the temporal bone whose clinical presentations were unrelated to facial nerve pathology. Facial nerve canals were assessed for the presence of fluid along each segment and meningoceles within either the labyrinthine segment (fluid-filled distention, $\geq 1.0$-mm diameter) or geniculate ganglion fossa (fluid-filled distention, $\geq 2.0$-mm diameter). If a meningocele was noted, images were assessed for signs of CSF leak.

RESULTS: Of 204 patients, 36 (17.6\%) had fluid in the labyrinthine segment of the facial nerve canal and 40 (19.6\%) had fluid in the geniculate ganglion fossa. Five (2.5\%) had meningoceles of the geniculate ganglion fossa; no meningoceles of the labyrinthine segment of the canal were observed. No significant difference was observed in the ages of patients with fluid in the labyrinthine segment of the canal or geniculate ganglion compared with those without fluid $(P=.177$ and $P=.896$, respectively). Of the patients with a meningocele, one had a partially empty sella and none had imaging evidence of CSF leak or intracranial hypotension.
\end{abstract}

CONCLUSIONS: Fluid within the labyrinthine and geniculate segments of the facial nerve canal is relatively common. Geniculate ganglion meningoceles are also observed, though less frequently. Such findings should be considered of little clinical importance without radiologic evidence of CSF otorrhea, meningitis, or facial nerve palsy.

M eningoceles of the facial nerve canal are a rare cause of CSF leak, with 15 reported cases in the literature. ${ }^{1-4}$ CSF leak in the context of facial nerve canal meningoceles occurs when the bony remodeling leads to dehiscence into the middle ear. ${ }^{5,6} \mathrm{~Pa}-$ tients may present with symptomatic unilateral conductive hearing loss, middle ear fluid, otorrhea, rhinorrhea (from CSF flow through the Eustachian tube), or facial nerve paresis. ${ }^{7,8}$ Commonly, patients are misdiagnosed with a middle ear effusion and are ultimately found to have a CSF leak when persistent clear otorrhea is noted after myringotomy. ${ }^{1}$ If otorrhea is present, preoperative meningitis has been reported in approximately half of patients. ${ }^{1}$ Imaging of facial nerve canal meningoceles typically demonstrates smooth bony enlargement of the geniculate gan-

Received March 19, 2019; accepted after revision June 17

From the Department of Neuroradiology (J.C.B., K.K., J.I.L.), Division of Biomedical Statistics and Informatics (J.R.G.), and Departments of Otorhinolaryngology (I.D., M.L.C.) and Neurosurgery (J.V.G.), Mayo Clinic, Rochester, Minnesota.

Please address correspondence to John C. Benson, MD, 723 6th St SW, Rochester, MN 55902; e-mail: benso905@umn.edu

http://dx.doi.org/10.3174/ajnr.A6133 glion fossa with internal signal that is isointense to CSF on all sequences; bony dehiscence may or may not be present. ${ }^{5,9}$

Observation of fluid or a meningocele within the facial nerve canal is a potential source of consternation to radiologists. No prior studies, to our knowledge, have described the incidence of such findings within the facial nerve canal in asymptomatic patients; the existing literature has focused on either microscopic analyses or meningoceles with bony dehiscence leading to symptomatic CSF leakage. Hence, this retrospective study sought to establish the prevalence of fluid or meningocele in the facial nerve canal in a cohort of patients asymptomatic for CSF leak, meningitis, or facial nerve palsy.

\section{MATERIALS AND METHODS Patient Selection}

Institutional review board approval was obtained for this study. A retrospective review was completed of all patients at our institution who underwent internal auditory canal protocol MR imaging between January 1, 2017, and June 30, 2018. Only patients with thin-slice (0.5-mm thickness with differing in-plane resolutions) T2-weighted axial images were included. Such thin-slice T2 images were completed using sampling perfection with application- 
optimized contrasts by using different flip angle evolutions (SPACE; Siemens, Erlangen, Germany), (CISS; Siemens), or FIESTA sequences. Patients were excluded for the following reasons: 1) the images were judged to be prohibitively degraded by artifacts (eg, motion), 2) imaging was obtained as part of a work-up for symptomatic otorrhea, or 3) imaging was performed to assess clinically suspected abnormalities of the seventh cranial nerve.

\section{Imaging and Electronic Medical Record Review}

Two neuroradiologists and a neuroradiology fellow reviewed MR images for the presence or absence of fluid within the labyrinthine, geniculate, and tympanic segments of the facial nerve canal and the presence or absence of meningoceles within the same locations. Meningoceles were defined as CSF-intensity fluid within a portion of the facial nerve canal that was widened on the basis of size criteria: $\geq 1.0$ - $\mathrm{mm}$ diameter of the labyrinthine segment of the facial nerve canal and $\geq 2.0$ - $\mathrm{mm}$ diameter of the geniculate ganglion fossa. ${ }^{10-12}$ Size criteria were based on mean \pm 2 SDs of normal labyrinthine size based on a study by Shin et $\mathrm{al}^{10}$ and on analyses of the geniculate ganglion fossa by $\mathrm{Gacek}^{11}$ and $\mathrm{Mu}$ et al. ${ }^{12}$ In patients determined to have meningoceles, images were secondarily assessed for imaging evidence of dehiscence and/or CSF (eg, middle ear effusion). If $\geq 1$ meningocele was detected, images were also assessed for the following: 1) secondary signs of CSF leak (eg, middle ear effusion, obvious bony dehiscence), 2) evidence of prior trauma or an operation, and 3) intracranial pathology that may have caused or suggested elevated intracranial pressure (eg, empty or partially empty sella, abnormal fluid within the optic nerve sheaths, tortuosity of the optic nerves, or slit-like ventricles). The body mass index of all patients was obtained via a retrospective review of the electronic medical record.

\section{Statistical Analysis}

Proportions of men and women with fluid in the specific anatomic compartments were compared using $\chi^{2}$ tests. Association of both age and body mass index with the presence or absence of fluid was tested using $t$ tests. Experiment-wide $\alpha$ was set at .05 . Statistical analyses were performed using SAS (Version 9.4; SAS Institute, Cary, North Carolina).

\section{RESULTS}

\section{Patient Characteristics and Presence of Fluid in the Facial Nerve Canal}

Two hundred four patients (408 temporal bones) were included in the study cohort with 107 women (52.5\%). The mean age was $53.3 \pm 10.1$ years ( $1 \mathrm{SD})$. CSF was present in the labyrinthine segment of the facial nerve canal in 36/204 patients (17.6\%) and was present in the geniculate ganglion fossa in 40/204 patients (19.6\%). No patients had CSF or meningoceles in the tympanic segment of the facial nerve canal. There was no significant difference in the ages of patients with fluid in the labyrinthine segment of the canal compared with those without fluid (55.4 \pm 10.3 versus $52.9 \pm 10.1$ years, respectively; $P=.177$ ), nor was there a significant difference in the ages of patients with fluid in the geniculate ganglion fossa compared with those without $(53.1 \pm 10.5$ versus $53.4 \pm 10.1$ years, respectively; $P=.896$ ).
Incidence of facial nerve canal fluid/meningocele ${ }^{a}$

\begin{tabular}{lccc}
\hline & $\begin{array}{c}\text { None } \\
\text { (No.) }\end{array}$ & $\begin{array}{c}\text { Unilateral } \\
\text { (No.) }\end{array}$ & $\begin{array}{c}\text { Bilateral } \\
\text { (No.) }\end{array}$ \\
\hline $\begin{array}{l}\text { Labyrinthine segment fluid } \\
\text { Geniculate ganglion fossa } \\
\text { fluid }\end{array}$ & $168(82.4 \%)$ & $22(10.8 \%)$ & $14(6.9 \%)$ \\
$\begin{array}{l}\text { Geniculate ganglion fossa } \\
\text { meningocele }\end{array}$ & $199(97.5 \%)$ & $5(2.5 \%)$ & $0(0.0 \%)$ \\
\hline
\end{tabular}

${ }^{a}$ Incidence of fluid signal in the facial nerve canal on 3D fast spin-echo T2 sequences in 204 patients. Meningoceles were defined on the basis of size criteria: $\geq 1.0-\mathrm{mm}$ diameter of the labyrinthine segment of the facial nerve canal, and $\geq 2.0-\mathrm{mm}$ diameter of the geniculate ganglion fossa. No meningoceles were observed within the labyrinthine segment.

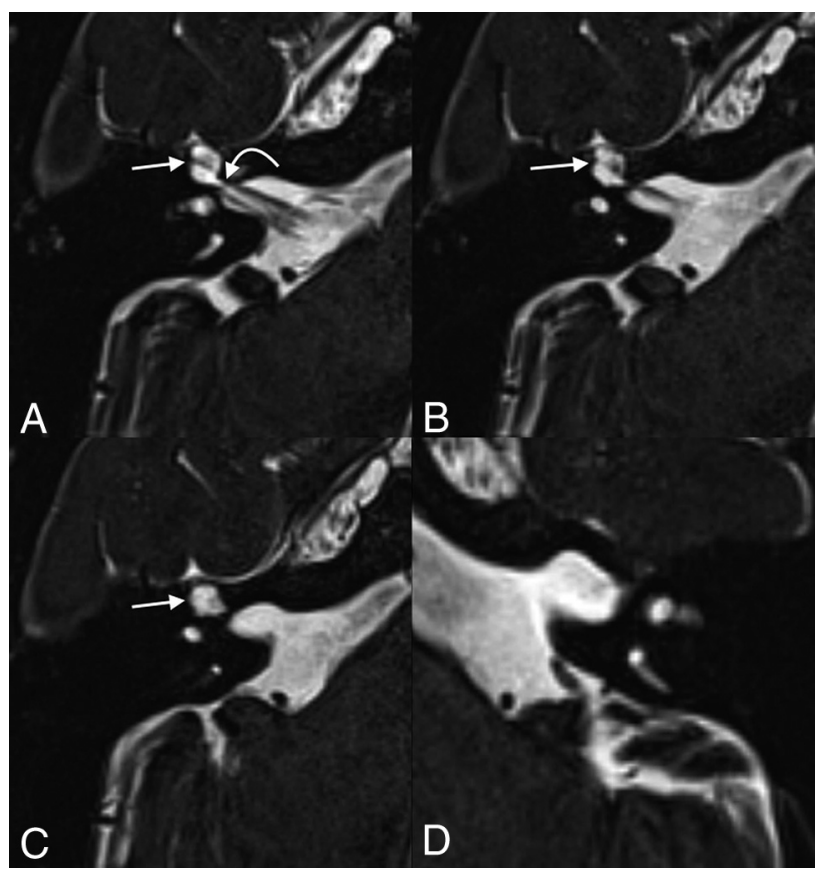

FIG 1. A 55-year-old woman who presented with persistent dizziness. From inferior to superior, axial T2 SPACE images demonstrate fluidfilled remodeling/expansion of the right geniculate ganglion fossa (straight arrows), compatible with a meningocele $(A-C)$. The labyrinthine segment of the facial nerve canal (curved arrow) is $0.9 \mathrm{~mm}$ in diameter, which is at the upper limit of normal but does not meet the defined size criteria for a meningocele. The normal left side is shown for comparison (D).

\section{Facial Nerve Canal Fluid Location, Laterality, and Meningoceles}

Location and laterality of fluid within the facial nerve canal are presented in the Table. Labyrinthine segment fluid was unilateral in $22 / 36(61.1 \%)$ patients and on the right in 12/22 (54.5\%). Geniculate ganglion fossa fluid was unilateral in 21/40 (52.5\%) patients and on the left in $11 / 21$ (52.4\%). In 21/40 (52.5\%) patients with fluid in the geniculate ganglion fossa, the finding was isolated, with no fluid in the labyrinthine segment or meningocele observed. No significant difference was observed between the rate of patients with fluid in the labyrinthine segment of the facial nerve canal based on sex $(P=$ .681). However, females were significantly more likely to have fluid in the geniculate ganglion fossa segment of the facial nerve canal than men $(26.2 \%$ versus $12.4 \%$, respectively; $P=.013)$.

Five patients within the cohort (2.5\%) had meningoceles, all of which were located in the geniculate ganglion fossa (Figs 1-3). Four of $5(80 \%)$ meningoceles were located on the right side. All 


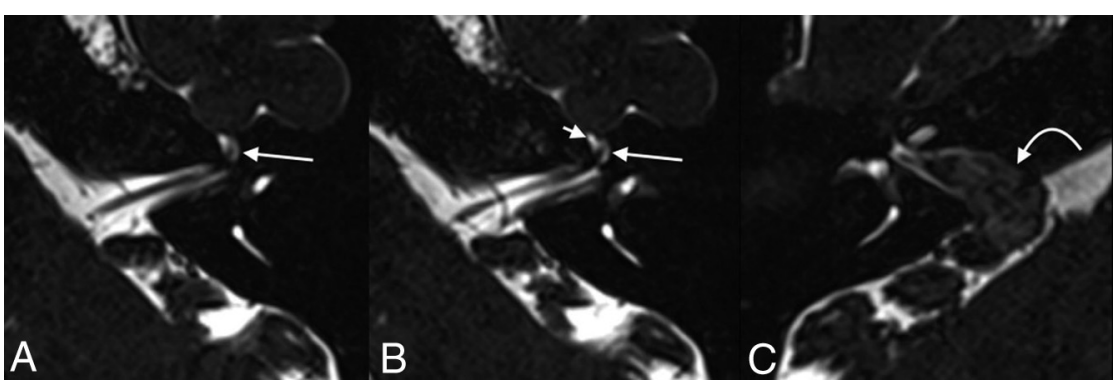

FIG 2. A 45-year-old woman who underwent imaging to follow up a known right vestibular schwannoma. Axial T2 SPACE images demonstrate fluid within the geniculate ganglion of the left facial nerve canal, with dilation measuring up to $2.7 \mathrm{~mm}$, compatible with a meningocele (long arrows, $A$ and $B$ ). Fluid is also seen tracking along the expected course of the proximal left greater superficial petrosal nerve (short arrow, $B$ ). The known vestibular schwannoma is seen in the contralateral right internal auditory canal, extending through the porus acusticus (curved arrow, C).

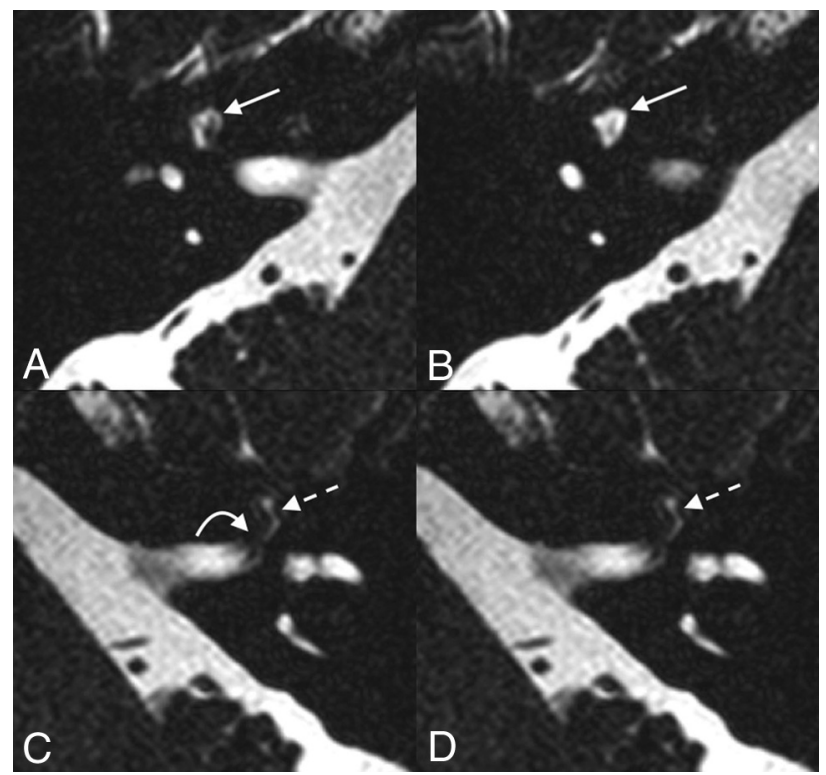

FIG 3. A 64-year-old woman who presented with bilateral sensorineural hearing loss. Axial T2 SPACE imaging demonstrates fluid-filled dilation of the right geniculate ganglion fossa, compatible with a meningocele (solid straight arrow, $A$ and $B$ ). Fluid is seen in the left labyrinthine (curved arrow, C) and geniculate (dashed straight arrow, $C$ and $D$ ) segments of the left facial nerve canal without remodeling/ dilation of the osseous canal.

(100.0\%) patients with meningoceles had fluid within the ipsilateral labyrinthine segments and geniculate ganglion fossa. None of the patients with meningoceles had evidence of bony dehiscence. No patients had meningoceles of the labyrinthine or tympanic segments of the facial nerve canal. None of the patients with meningoceles had secondary intracranial findings to suggest clinically occult CSF leak or intracranial hypotension, nor did these patients have imaging evidence of prior trauma or an operation. Of the patients with meningoceles, one had a contralateral vestibular schwannoma. One patient with a meningocele had a partially empty sella. There was no significant difference in the body mass indexes among patients with fluid in the facial nerve canal or geniculate ganglion fossa versus those without fluid $(P=.584$ and $P=.688$, respectively), nor was there a difference between patients with meningoceles and those without $(P=.566)$.

\section{DISCUSSION}

This study set out to describe the prevalence of asymptomatic fluid and meningoceles within the facial nerve canal. We found that fluid is commonly present in the facial nerve canal in asymptomatic patients, occurring with near-equal incidence in the labyrinthine segment and geniculate ganglion fossa. To our knowledge, this is the first report of the incidental presence of fluid or meningocele in the facial nerve canal on MR imaging. Our results suggest that these are normal variants and should not be considered an unexpected or actionable finding.

According to multiple authors, CSF is prevented from flowing into the facial nerve canal in healthy patients by 2 anatomic barriers: An arachnoid sheath at the meatal foramen (the anatomic proximal end of the facial nerve canal) seals the facial nerve in the canal, and the facial nerve nearly fills the entire diameter of the relatively small osseous canal, thereby excluding CSF flow. ${ }^{1,13-15}$ However, a large histologic study of temporal bones by Gacek ${ }^{11}$ found at least some extension of the subarachnoid space along the labyrinthine segment of the facial nerve canal in $88 \%$ of patients. Most of the remaining patients who had subarachnoid space extension to, or past, the geniculate ganglion in that study had intracranial pathology that may have been associated with intracranial hypertension. ${ }^{11}$ In our study, the incidence of fluid within the labyrinthine segment of the facial nerve canal is much lower than that observed by Gacek. Although the disparity between the study by Gacek and the current study is unknown, it is likely that the spatial and contrast resolution of MR imaging is less sensitive to fluid than histologic analysis. In the current study, only 1 patient had a partially empty sella without clinical evidence of pseudotumor cerebri; there was otherwise no imaging evidence of intracranial hypertension among patients with meningoceles. Furthermore, it is possible that both fluid and meningoceles within the facial nerve canal represent sequelae of mild or compensated intracranial hypertension, similar to petrous apex cephaloceles and arachnoid granulations. ${ }^{5,16}$

Although it is unknown why fluid along the labyrinthine and/or geniculate segments of the facial nerve was observed in spontaneous cases, it is possible that either congenital enlargement of the facial nerve canal or increased intracranial pressure contributed to the findings. ${ }^{17}$ Even slight congenital enlargement of the facial nerve canal could allow the subarachnoid space, and thereby CSF, to extend along the course of the facial nerve. Pressure and repetitive pulsations related to CSF could lead to remodeling of the osseous canal and dehiscence/fistulization into adjacent structures such as the middle ear. ${ }^{13}$ It is notable that while meningoceles were observed in the geniculate ganglion fossa, none were seen in the labyrinthine segment of the facial nerve canal. It is possible that the architecture of the geniculate fossa is more susceptible to bony remodeling related to high-pressure environments in accordance with Bernoulli's principle: Fluid within a system is at higher pressure as the diameter of the canal increases, and the geniculate ganglion fossa is larger than the laby- 
rinthine segment of the facial nerve canal. It is also possible that geniculate ganglion dehiscence plays a role; a prior study by Isaacson and $\mathrm{Vrabec}^{18}$ found geniculate ganglion dehiscence to be a common radiographic finding, present in $14.5 \%$ of all patients.

This study has limitations shared by any retrospective review. Determination of CSF within the facial nerve canal was based on imaging tools with intrinsic (spatial and contrast resolution) and situational (bone-air interface artifacts) shortcomings compared with the histologic standard; laboratory analysis would be required to confirm that the observed fluid was CSF. Next, although the differentiation between CSF within the facial nerve canal and meningocele was sharply defined in this study based on canal diameter, the 2 entities likely exist on a spectrum; a patent facial nerve canal allows CSF flow, which may cause bony remodeling and hence meningocele formation across time-again, in accordance with Bernoulli's principle. Also, the opening CSF pressure was not available for review, limiting the ability of this study to correlate any findings with intracranial hyper- or hypotension. Finally, as stated above, the patient population of the study had dedicated internal auditory canal protocol MR imaging, limiting the ability to assess evidence of or pathology potentially related to intracranial hypertension.

\section{CONCLUSIONS}

Fluid in the labyrinthine and geniculate segments of the facial nerve canal is a relatively common incidental finding on temporal bone MRIs and presumably represents CSF. Meningoceles of the geniculate ganglion fossa, too, are observed in asymptomatic patients, though less frequently. In the absence of clinical or radiologic evidence of associated CSF otorrhea, these findings should be considered incidental variants.

\section{REFERENCES}

1. Dey J, Van Gompel JJ, Lane JI, et al. Fallopian canal meningocele with spontaneous cerebrospinal fluid otorrhea: case report and systematic review of the literature. World Neurosurg 2019;122:e285-90 CrossRef Medline

2. Mong S, Goldberg AN, Lustig LR. Fallopian canal meningocele: report of two cases. Otol Neurotol 2009;30:525-28 CrossRef Medline

3. Kong WK, Lee $\mathrm{CH}$, Eunhye $\mathrm{Y}$, et al. Unruptured translabyrinthine meningocele without CSF otorrhea. Int J Pediatr Otorhinolaryngol 2014;78:556-59 CrossRef Medline

4. Franco-Vidal V, Baretto GP, Vignes JR, et al. Spontaneous cerebrospinal fluid fistula through a congenitally patent facial nerve canal: incrimination of idiopathic intracranial hypertension. Otol Neurotol 2009;30:123-24 CrossRef Medline

5. Petrus LV, Lo WW. Spontaneous CSF otorrhea caused by abnormal development of the facial nerve canal. AJNR Am J Neuroradiol 1999; 20:275-77 Medline

6. Truesdale CM, Peterson RB, Hudgins PA, et al. Internal auditory canal meningocele-perilabyrinthine/translabyrinthine fistula: case report and imaging. Laryngoscope 2016;126:1931-34 CrossRef Medline

7. Alonso RC, de la Peña MJ, Caicoya AG, et al. Spontaneous skull base meningoencephaloceles and cerebrospinal fluid fistulas. Radiographics 2013;33:553-70 CrossRef Medline

8. Remenschneider AK, Kozin ED, Curtin H, et al. Histopathology of idiopathic lateral skull base defects. Laryngoscope 2015;125:1798 806 CrossRef Medline

9. Gray BG, Willinsky RA, Rutka JA, et al. Spontaneous meningocele, a rare middle ear mass. AJNR Am J Neuroradiol 1995;16:203-07 Medline

10. Shin KJ, Gil YC, Lee JY, et al. Three-dimensional study of the facial canal using microcomputed tomography for improved anatomical comprehension. Anat Rec (Hoboken) 2014;297:1808-16 CrossRef Medline

11. Gacek RR. Anatomy and significance of the subarachnoid space in the fallopian canal. Am J Otol 1998;19:358-65 Medline

12. Mu X, Quan Y, Shao J, et al. Enlarged geniculate ganglion fossa: CT sign of facial nerve canal fracture. Acad Radiol 2012;19:971-76 CrossRef Medline

13. Foyt D, Brackmann DE. Cerebrospinal fluid otorrhea through a congenitally patent fallopian canal. Arch Otolaryngol Head Neck Surg 2000;126:540-42 CrossRef Medline

14. Mortazavi MM, Latif B, Verma K, et al. The fallopian canal: a comprehensive review and proposal of a new classification. Childs Nerv Syst 2014;30:387-95 CrossRef Medline

15. Cavusoglu M, Duran S, Hatipoglu HG, et al. Petrous apex cephalocele: contribution of coexisting intracranial pathologies to aetiopathogenesis. Br J Radiol 2015;88:20140721 CrossRef Medline

16. Watane GV, Patel B, Brown D, et al. The significance of arachnoid granulation in patients with idiopathic hypertension. J Comput Assist Tomogr 2018;42:282-85 CrossRef Medline

17. Brainard L, Chen DA, Aziz KM, et al. Association of benign intracranial hypertension and spontaneous encephalocele with cerebrospinal fluid leak. Otol Neurotol 2012;33:1621-24 CrossRef Medline

18. Isaacson B, Vrabec JT. The radiographic prevalence of geniculate ganglion dehiscence in normal and congenitally thin temporal bones. Otology Neurotol 2007;28:107-10 CrossRef Medline 